\title{
AVALIAÇÃO: NOTAS E MÉTODOS DE AVALIAÇÃO NAS SÉRIES INICIAIS DO ENSINO FUNDAMENTAL
}

\author{
Damiana Correia MARTINS* \\ Douglas Carvalho De MENEZES ${ }^{* *}$
}

Resumo: Este trabalho visa descrever como é a avaliação escolar nas séries inicias do ensino fundamental, observando os métodos e práticas que possibilitam avaliar o estudante de forma satisfatória, sem desmotivá-lo. Além disso, refletir sobre as formas de avaliar para posteriormente distribuir as notas ou conceitos. Neste aspecto, entender a importância das notas e como ela se deve dar para que faça sentido no processo ensino-aprendizagem. Refletir sobre a avaliação de modo geral, entender as diversas formas de avaliar dos professores é buscar qual a melhor forma de avaliação olhando para a realidade do aluno e rever o processo de aprendizagem como algo que se deve estar articulado com toda a escola. O professor é um formador que deve entender a avaliação, refletir sobre suas práticas para moldá-las de acordo com as necessidades da sala de aula, buscando uma aprendizagem significativa e contínua, que priorize o desenvolvimento do estudante em todos os aspectos.

\footnotetext{
* Licenciatura plena em Pedagogia. Faculdade de Educação e Estudos Sociais de Uberlândia - UNIPAC.dami_martins@ @otmail.com

** Mestre em educação pelo programa de Pós-graduação em Educação da universidade federal de Uberlândia UFU. douglasmatufu@yahoo.com.br
} 
Palavras-chave: Avaliação educacional; Ensino-aprendizagem; Aluno; Professor.

\begin{abstract}
This paper aims to describe how the school evaluation is in the initial grades of elementary school, observing the methods and practices that make it possible to evaluate the student in a satisfactory way, without demotivating him. In addition, reflect on the ways to evaluate and later distribute the notes or concepts. In this aspect, understand the importance of grades and how it should be given to make sense in the teaching-learning process. To reflect on the evaluation in general, to understand the different ways teachers evaluate is to seek the best form of evaluation looking at the reality of the student and review the learning process as something that should be articulated with the whole school. The teacher is a trainer who must understand the evaluation, reflect on its practices to shape them according to the needs of the classroom, seeking a meaningful and continuous learning that prioritize student development in all aspects.
\end{abstract}

Palavras-chave: Educational evaluation; Teaching-learning; Student; Teacher 


\section{INTRODUÇÃO}

Avaliar é observar, diagnosticar uma vivência, com o objetivo de obter o melhor resultado, sendo assim ela não pode ser classificatória, pois ela é utilizada para verificação do que se quer alcançar visando uma melhoria contínua, através de coleta de informações e observações que são analisadas. Essas análises partem de um padrão de qualidade estabelecido de acordo com o que se é avaliado, e assim define se deve manter, melhorar ou mudar algo.

A avaliação educacional, em geral, e a avaliação de aprendizagem escolar, em particular, são meios e não fins, em si mesmas, estando assim delimitadas pela teoria e pela prática que as circunstancializam. Desse modo, entendemos que a avaliação não se dá nem se dará num vazio conceitual, mas sim dimensionada por um modelo teórico de mundo e de educação, traduzido em prática pedagógica (LUCKESI, 2000, p. 28).

Pensando nisso devemos olhar a avaliação na realidade educacional em que se encontra com a sensibilidade de perceber, em todos os aspectos, o educando com trabalhos pedagógicos diferenciados em que busque a transformação. O professor deve estar disposto a conhecer a realidade do aluno e a partir disso propor novos caminhos, novas aprendizagens que possam ser construídas juntos.

Como um dos pontos que busca a qualidade da educação, a avaliação nos mostra informações relevantes sobre o processo de 
formação do indivíduo e com isso cada dia mais temos estudos sobre avaliação na educação, porém ainda há muito que se discutir sobre o assunto já que na maioria das vezes essas avaliações parecem se basear nas concepções de cada docente. Para avaliar um aluno é preciso diagnosticar o que ele já conhece sobre o conteúdo estudado.

E daí, a partir do conhecimento do aluno, é que se deve introduzir o estudo e consequentemente avalia-lo, para isso deve-se ter bem definido o objetivo a ser alcançado, demarcando as possibilidades de melhoria para a aprendizagem, pois assim a avaliação fará sentido no processo de construção da educação.

O presente artigo trata dos resultados de uma pesquisa sobre os métodos utilizados de avaliação dos alunos do $5^{\circ}$ ano do Ensino Fundamental I. Essa pesquisa foi norteada pela busca das respostas da seguinte indagação: Quais os métodos existentes de avaliação que contribuem para a aprendizagem do aluno?

Diante desta questão, pretendeu-se com o estudo realizado, pesquisar sobre os métodos utilizados de avaliação dos alunos do $5^{\circ}$ ano do Ensino Fundamental I para entender se estes contribuem para a aprendizagem dos alunos e esclarecer o sentido dos conceitos (notas) aplicados aos alunos no processo de ensino-aprendizagem. Além disso, também se buscou de forma específica, pesquisar a importância da avaliação escolar, se os métodos de avaliação utilizados pelo professor 
são eficazes a aprendizagem do aluno, bem como examinar e refletir sobre o objetivo dos conceitos (notas) para os alunos dos anos iniciais.

$\mathrm{O}$ estudo dos métodos de avaliação surgiu da necessidade de entender como é o "olhar" dos professores perante o aluno para avaliálo. O que é observado para classificar os alunos dos anos iniciais como A, B ou C? Quais os objetivos destes conceitos e dos métodos de avaliação? Portanto, primeiramente é preciso entender os conceitos de avaliação, diante de alguns autores. Refletir o sentido de avaliação, entender o processo como uma forma de diagnosticar e incluir os alunos, servindo como apoio ao professor sem que o mesmo se sinta excluído.

Para obter respostas ao problema da pesquisa e alcançar os objetivos pretendidos será feito uma pesquisa bibliográfica de vários autores (Luckesi, Sordi e Hoffmann) sobre avaliação para analisar os métodos e práticas que podem ser utilizadas para avaliar o aluno, como também estudo sobre o papel dos professores no processo de avaliação, para entender como eles avaliam o seu estudante. Refletir sobre as práticas da avaliação, e qual o objetivo de dar notas, conceituar o aluno. Nesse sentido, pesquisaremos a avaliação no processo da educação, como elemento fundamental para a aprendizagem dos estudantes. 


\section{DESENVOLVIMENTO}

\subsection{A importância da avaliação escolar}

Quando falamos de educação pensamos no futuro das pessoas, do país, nas perspectivas de uma vida melhor e do crescimento das pessoas enquanto cidadãos críticos e reflexivos. Desta forma, estamos preocupados com o ensino-aprendizagem, com uma educação de qualidade.

No processo de ensino-aprendizagem o fator mais importante são os objetivos alcançados pelos alunos, e através destes resultados fazer uma reflexão crítica da aprendizagem dos mesmos. A avaliação do estudante tem a função de auxiliar na construção da aprendizagem, pois através dela os processos e práticas pedagógicas são também automaticamente avaliados e repensados.

Entendo que a avaliação deve ser usada no processo de construção do desenvolvimento do estudante, deixando de lado o autoritarismo dos processos rígidos e aplicados sem quaisquer preocupações com a realidade do aluno, partimos então de uma avaliação que tenha característica diagnóstica e possa intermediar as vivências dos alunos com as práticas realizadas em sala de aula. Segundo os Parâmetros Curriculares Nacionais (PCN) indica que: 
Necessária à disponibilidade para o envolvimento do aluno na aprendizagem, o empenho em estabelecer relações entre o que já sabe e o que está aprendendo. Essa aprendizagem exige uma ousadia para se colocar problemas, buscar soluções, e experimentar novos caminhos, de maneira diferente da aprendizagem mecânica, no qual o aluno limita seu esforço apenas em memorizar ou estabelecer relações diretas e superficiais (BRASIL, 1997, p.99).

O professor deve ser mediador da aprendizagem, construir a aprendizagem juntamente com o estudante, valorizando seus conhecimentos adquiridos dentro e fora da escola. Para essa busca de soluções e novos experimentos é preciso repensar as práticas pedagógicas como também as formas de avaliação, pois a aprendizagem é contínua.

O sistema de ensino ficou de certa forma automático, o aluno estuda para passar de série, visto como uma promoção ao estudante que saiu bem nas provas, teve bom comportamento e fez as atividades de forma satisfatória, ou seja, ele cumpriu com suas obrigações escolares e isso fez com que ele fosse aprovado. Os pais também veem desta forma, deixando de observar a aprendizagem. A avaliação escrita, principalmente, é vista como um exame para aprovação do estudante. O aluno deve ser avaliado de forma a valorizar seus conhecimentos já adquiridos, suas competências e habilidades, para que ele veja sentido no que está aprendendo. 
Dessa forma, Luckesi (2002) fala sobre o tipo de avaliação que leva em consideração a promoção através das notas sem priorizar a aprendizagem.

Pais, sistema de ensino, profissionais de educação, professores e alunos, todos tem suas atenções centradas na promoção, ou não, do estudante de uma série de escolaridade para outra. O sistema de ensino está interessado nos percentuais de aprovação/reprovação do total dos educandos; os pais estão desejosos de que seus filhos avancem nas séries de escolaridade; os professores se utilizam permanentemente dos procedimentos de avaliação como elementos motivadores dos estudantes, por meio da ameaça; os estudantes estão sempre na expectativa de virem a ser aprovados ou reprovados e, para isso, servem-se dos mais variados expedientes. $\mathrm{O}$ nosso exercício pedagógico escolar é atravessado mais por uma pedagogia do exame que por uma pedagogia do ensino/aprendizagem (LUCKESI, 2002, p. 18).

O ensino ainda é avaliado separando o que o aluno aprendeu e o que não aprendeu, deixando de observar as formas de aprendizagem, assim como também o estudante que aprendeu e o que estudante que não aprendeu. A avaliação serve para rever as práticas e buscar alternativas para os objetivos a serem alcançados, não deve ser classificatória, mas sim inclusiva e diagnóstica, servindo de suporte em suas diversas formas de avaliar. Dessa maneira, para Luckesi (1990), 
A avaliação, diferentemente da verificação, envolve um ato que ultrapassa a obtenção de configuração do objeto, exigindo decisão do que fazer ante ou com ele. A verificação é uma ação que "congela" o objeto; a avaliação, por sua vez, direciona o objeto numa trilha dinâmica de ação (LUCKESI, 1990, p. 76).

A escola no Brasil em geral mostra que é utilizado à verificação e não a avaliação, obtendo então a aprovação ou reprovação do aluno.

\subsection{Métodos de avaliação}

O aluno faz parte do processo da avaliação escolar, porém não é somente ele avaliado, pois a partir de uma avaliação contínua com foco nos objetivos a ser alcançada, a escola como todo o processo de ensino-aprendizagem e os envolvidos neste processo automaticamente estão sendo avaliados. Muitas vezes ouvimos que o estudante não atingiu o conceito ou nota necessária para um bom resultado, mas não podemos esquecer que avaliação serve também para ver o que a escola e equipe pedagógica pode fazer para melhorar os resultados de aprendizagem. Assim, percebemos como são importantes os métodos de avaliação, pois eles dependem das finalidades e objetivos pretendidos. 
Ao falar em métodos de avaliação automaticamente nós nos deparamos ou pensamos nas avaliações escritas, que em alguns casos valem nota, não podemos nos esquecer da principal construção da aprendizagem, o cotidiano com o aluno. As práticas no dia a dia da sala de aula, onde o professor valoriza as vivencias com o estudante, fazendo assim as intervenções para uma aprendizagem espontânea, principalmente que devem ser avaliadas.

O professor constrói conhecimentos e sentidos à avaliação com base em suas observações e conhecimentos. Neste contexto, Sordi (2001, p.173) afirma que "uma avaliação espelha um juízo de valor, uma dada concepção de mundo e de educação, e por isso vem impregnada de um olhar absolutamente intencional que revela quem é o educador quando interpreta os eventos da cena pedagógica." O educador utiliza de seus conhecimentos, muitas vezes de experiências vividas enquanto eram alunos, para a avaliação enquanto professor. $\mathrm{O}$ docente traz suas experiências arraigadas para suas práticas, deixando prevalecer a avaliação somativa, materializando-se totalmente pela nota do aluno. Conforme os estudos feitos por Perrenoud (1999), as práticas de avaliação podem ser formativa e somativa.

Dessa maneira, Sordi (2001) fala o seguinte sobre a somativa:

Esta se relaciona mais ao produto demonstrado pelo aluno em situações previamente estipuladas e definidas pelo professor, e se materializa na nota, objeto de desejo 
e sofrimento dos alunos, de suas famílias e até do próprio professor. Predomina nessa lógica o viés burocrático que empobrece a aprendizagem, estimulando ações didáticas voltadas para o controle das atividades exercidas pelo aluno, mas não necessariamente geradoras de conhecimento (SORDI, 2001, p.173).

Está bem explicito que essa avaliação somativa é resultado de atividades avaliativas determinadas pelo professor obtendo-se a nota, sendo classificatória. Já na avaliação formativa, ela está preocupada com o processo de formação do aluno enquanto cidadão na busca de conhecimento através de seus conhecimentos prévios, com objetivo de se inserir no processo de formação de sua aprendizagem, sendo qualitativa. Essa avaliação poderá ser por meio de atividades diversas como: debates, trabalhos individuais e em grupos, pesquisas, atividades escritas e orais, participação do aluno, dentre outras que serão planejadas de acordo com o perfil dos estudantes.

\subsection{Objetivo dos conceitos (notas)}

A avaliação escolar poderá se dar por meio de diversas atividades. E o resultado dessas avaliações nas séries iniciais são os conceitos: A, B ou C. Para analisarmos o objetivo desses conceitos primeiramente destacamos que na Lei de Diretrizes e Bases da 
Educação - LDB (Lei n. 9.394/96) estabelece o seguinte sobre a verificação da avaliação:

A verificação do rendimento escolar observará seguintes critérios: avaliação contínua e cumulativa do desempenho do aluno, com a prevalência dos aspectos qualitativos sobre os quantitativos e dos resultados ao longo do período sobre o de eventuais provas finais (BRASIL, 1996, art. 24).

Segundo a LDB a avaliação deve ser pensada como uma ferramenta para auxiliar o professor no desempenho do aluno, prevalecendo à qualidade da aprendizagem no lugar dos conceitos atribuídos às atividades. Vale também destacar que nos Parâmetros Curriculares Nacionais (BRASIL, 1997) estabelece que a avaliação deva buscar o sucesso e do aluno como também orientar as práticas pedagógicas.

A avaliação vai além da visão tradicional, que focaliza o controle externo do aluno, através de notas ou conceitos, para ser compreendida como parte integrante e intrínseca ao processo educacional. A avaliação ao não se restringir ao julgamento sobre sucessos ou fracassos do aluno, é compreendida como um conjunto de atuações que tem função de alimentar, sustentar e orientar a orientação pedagógica (BRASIL, 1997, p.55).

A avaliação pode se dar de forma espontânea, a critério do professor, ficou como algo "perdido", pois cada professor aplica suas 
observações e avaliações da forma que aprendeu ou que julga mais ideal, assim Hoffmann (2000) diz que:

Percebo, em contato com os professores que o "fenômeno avaliação" é, hoje, um fenômeno indefinido. Professores e alunos que usam o termo atribuem-lhe diferentes significados, relacionados principalmente, aos elementos constituintes da prática avaliativa tradicional: prova, nota, conceito, boletim, recuperação, reprovação. Estabelecem uma relação direta entre tais procedimentos e avaliação, com uma grande dificuldade em compreender tal equívoco. Dar nota é avaliar, fazer prova é avaliar, o registro das notas, denomina-se avaliação. Ao mesmo tempo, vários significados são atribuídos ao termo: análise de desempenho, julgamento de resultados, medida de capacidade, apreciação do "todo" do aluno. Quando questiono diretamente o significado da palavra avaliação recebo, por vezes, tantas definições quantos são os professores presentes os encontros (HOFFMANN, 2000, p. 13).

São muitas as discussões sobre avaliação, mas chegamos sempre numa mesma linha de prioridade, a nota do aluno. Os pais também querem que seu filho obtenha a maior nota possível e seguir para o próximo ano escolar. Neste sentido, sabemos que o professor deve repensar suas formas de avaliar, refletir sobre o objetivo final, deixando de ter como prioridade apenas a nota do aluno. $\mathrm{O}$ professor não é mais o dono do saber, o responsável por ensinar, ele é mediador em que deve estimular o estudante a pensar e estabelecer uma conexão entre os conteúdos e a sua vivência. 
A avaliação nas séries iniciais é um processo bem mais minucioso, pois estamos lidando com crianças que vieram da educação infantil e não entendem esse processo. Além do mais deve ser algo prazeroso, que estimule a criança a se desenvolver e criar seus conhecimentos. Deve-se ter como princípio a avaliação processual, participativa, formativa, cumulativa e diagnóstica, com práticas e instrumentos de avaliação diversos. Em relação ao Ensino Fundamental, destacamos na LDB (Lei n. 9.394/96):

Do Ensino Fundamental. Art. $32^{\circ}$. O ensino fundamental, com duração mínima de oito anos, obrigatório e gratuito na escola pública, terá por objetivo a formação básica do cidadão, mediante: I - o desenvolvimento da capacidade de aprender, tendo como meios básicos o pleno domínio da leitura, da escrita e do cálculo; II - a compreensão do ambiente natural e social, do sistema político, da tecnologia, das artes e dos valores em que se fundamenta a sociedade; III - o desenvolvimento da capacidade de aprendizagem, tendo em vista a aquisição de conhecimentos e habilidades e a formação de atitudes e valores; IV - o fortalecimento dos vínculos de família, dos laços de solidariedade humana e de tolerância recíproca em que se assenta a vida social (BRASIL, 1996).

Com a LDB percebemos que a avaliação deve estar mais ligada ao desenvolvimento do aluno enquanto cidadão, compreendendo o meio em que vive enquanto sociedade, formando seus valores, direitos e deveres, do que avaliar o conteúdo estudado nas disciplinas. 


\section{CONSIDERAÇÕES FINAIS}

A avaliação é um processo amplo o qual se dá vários estudos e reflexões, como também é de suma importância para aprendizagem dos alunos, mas depende da forma com que ela é aplicada. Diante deste artigo vimos que se deve ter uma visão crítica e reflexiva das práticas aplicadas na avaliação escolar, para entender a realidade da escola e dos alunos, e assim buscar uma avaliação que faça parte da construção do indivíduo. Para isso a avaliação deve fazer sentido na vida do estudante, assim como a aprendizagem, dessa maneira o professor deve partir sempre dos conhecimentos e vivências do aluno, sendo mediador neste processo.

As avaliações ficaram automatizadas, de forma que o aluno estuda para passar de série, com isso percebemos que o professor juntamente com toda equipe escolar deve planejar, ter um novo olhar para a avaliação e para o estudante, entendendo que o conhecimento, o desenvolvimento do estudante enquanto cidadão, é mais importante do que as notas e mais do que passar para uma nova série. A escola, ao começar a mudar essa visão consequentemente estará contribuindo para uma educação que visa o conhecimento e valoriza o que o estudante já conhece. 
Quando avaliamos o aluno, a escola toda estará sendo avaliada. As práticas de ensino, o trabalho em conjunto com toda equipe pedagógica, as estratégias de intervenções, os projetos, dentre outros. Para que isso ocorra de forma satisfatória a escola e a equipe devem estar alinhadas aos objetivos que querem alcançar e preocuparem-se com a formação do aluno, sem deixar que a nota seja o objetivo final.

Assim a avaliação deve ser vista como um diagnóstico, um apoio para observar o que pode ser mudado na escola, na sala de aula, e como trabalhar com o aluno de acordo com sua realidade. É importante lembrar que a avaliação é contínua, não podendo ser considerada apenas a avaliação escrita, pois esta é só mais uma ferramenta de diagnóstico.

O aluno é o principal objetivo da escola e da educação, sendo que a escola está à disposição dele para ajudá-lo a se desenvolver enquanto cidadão. Muitas vezes deixamos de vê-lo como o principal agente nesse processo, sendo que é ele o construtor de seu próprio conhecimento, e o professor apenas um mediador.

Nas séries iniciais a criança ainda não está preparada nem para entender o que é avaliação, por isso ela deve acontecer naturalmente, sem necessidade de falar que a criança está sendo avaliada e através de observações do seu desenvolvimento diário. A avaliação serve para 
buscar o sucesso do aluno, através de uma reorganização das práticas pedagógicas de acordo com suas necessidades.

\section{REFERÊNCIAS}

BRASIL. Lei de Diretrizes e Bases. $n^{\circ}$. 9394/96, de 20 de dezembro de 1996. Estabelece as Diretrizes e Bases da Educação Nacional. Brasília/DF: 1996.

BRASIL. Parâmetros curriculares nacionais: introdução aos parâmetros curriculares nacionais. Brasília: MEC/SEF, 1997.

HOFFMANN, J. Avaliação: Mito e Desafio. Uma perspectiva construtivista. Porto Alegre: Mediação, 2000.

LUCKESI, C.C. Avaliação da aprendizagem escolar. São Paulo: Cortez, 2000.

LUCKESI. C.C. Verificação ou avaliação: o que pratica a escola? A construção do professor de ensino e avaliação. Ideias, n. 8, p. 7180. São Paulo: FDE, 1990.

LUCKESI, C. C. Avaliação da aprendizagem escolar: estudos e proposições. São Paulo: Cortez 2002.

SORDI, M. R. L. Alternativas propositivas no campo da avaliação: Por que não? In S. Castanho \& M. E. Castanho (Orgs.). Temas e 
textos em metodologia do Ensino Superior. Campinas, São Paulo: Papirus, 2001.

PERRENOUD, P. Avaliação da excelência: a regulação das aprendizagens entre duas lógicas. Porto Alegre: Art Méd, 1999. 